\title{
Role of carnoy's solution in the treatment of keratocystic odontogenic tumor: A systematic review
}

\author{
Álvaro Díaz-Belenguer ${ }^{1}$, Alba Sánchez-Torres ${ }^{2}$, Cosme Gay-Escoda ${ }^{3}$ \\ ${ }^{1}$ DDS. Fellow of the Master's Degree Program in Oral Surgery (EHFRE International University/FUCSO) \\ ${ }^{2}$ DDS. Fellow of the Master of Oral Surgery and Orofacial Implantology. School of Dentistry, University of Barcelona, Spain \\ ${ }^{3} \mathrm{MD}, \mathrm{DDS}, \mathrm{MS}, \mathrm{PhD}$, EBOS. Chairman and Professor of the Oral and Maxillofacial Surgery Department, School of Dentistry, \\ University of Barcelona. Director of Master's Degree Program in Oral Surgery and Implantology (EHFRE International Uni- \\ versity/FUCSO). Coordinator/Researcher of the IDIBELL Institute. Head of Oral and Maxillofacial Surgery and Implantology \\ Department of the Teknon Medical Center, Barcelona, Spain
}

Correspondence:

Teknon Medical Center

C/ Vilana 12 ,

08022 - Barcelona, Spain

cgay@ub.edu

Díaz-Belenguer Á, Sánchez-Torres A, Gay-Escoda C. Role of carnoy’s solution in the treatment of keratocystic odontogenic tumor: A systematic review. Med Oral Patol Oral Cir Bucal. 2016 Nov 1;21 (6):e689-95.

http://www.medicinaoral.com/medoralfree01/v21i6/medoralv21i6p689.pdf

Received: 24/01/2016

Accepted: 09/03/2016

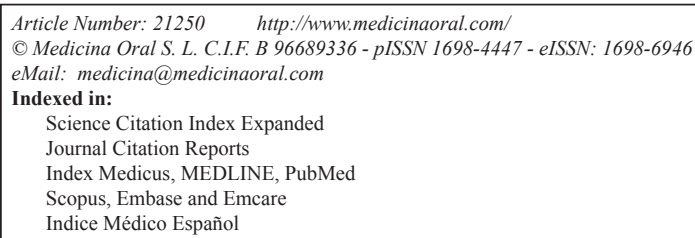

\begin{abstract}
Introduction and Objective: The keratocystic odontogenic tumor is a benign but aggressive neoplasm. As enucleation alone obtains high recurrence rates, some adjuvant treatments such as Carnoy's solution have been proposed. The aim of this study is to evaluate the reduction of recurrences with the use of Carnoy's solution as adjuvant in the treatment of keratocystic odontogenic tumors.

Material and Methods: An electronic search in Pubmed (MEDLINE), ScienceDirect and Cochrane databases was conducted with the key words "odontogenic keratocyst", "keratocystic odontogenic tumor", "carnoy's solution", "treatment" and "enucleation". The inclusion criteria were clinical studies using Carnoy's solution as adjuvant for the treatment of keratocystic odontogenic tumors, published in English, including at least 10 patients. Articles with an unclear reporting of the treatment applied, nonhuman studies, case reports and lesions associated to Gorlin-Goltz syndrome were excluded.

Results: All the studies included were case series. The recurrence rate of enucleation ranged from $0 \%$ to $58.8 \%$. With the only use of Carnoy's solution as adjuvant treatment to the enucleation, recurrences varied from $0 \%$ to $100 \%$. The use of $\geq 2$ adjuvant treatments reduced the range between $0 \%$ and $7.9 \%$.

Conclusions: The use of Carnoy's solution as adjuvant therapy for the treatment of keratocystic odontogenic tumor has a grade $\mathrm{C}$ recommendation.
\end{abstract}

Key words: Carnoy's solution, keratocystic odontogenic tumor, treatment, recurrence. 


\section{Introduction}

The odontogenic keratocyst was first described by Philipsen in 1956 (1). From the two histologic variants, the orthokeratinized one appears in $12 \%$ of cases and the parakeratinized variant of this entity in $90 \%$ of them $(1,2)$. The later was renamed as keratocystic odontogenic tumor (KOT) by the World Health Organization (WHO) in 2005 that is a benign but aggressive neoplasm of odontogenic origin, histologically characterized by a thin parakeratinized stratified squamous epithelium (1-9). Some cell proliferation markers as Ki-7, PCNA or p53 have been found in the suprabasal zone (10). This tumor can appear as a single or multiple lesions and even, as a part of nevoid basal cell carcinoma syndrome or Gorlin-Goltz syndrome $(1,4,10)$. The higher incidence appears in patients ranging from 20 to 40 years old and its prevalence is higher in men than in women, in a $2: 1$ proportion $(9,11)$.

The histopathological analysis is necessary to establish the definitive diagnosis. An incisional or excisional biopsy, or a fine-needle aspiration biopsy are the most used techniques to obtain a sample (2), although the presence of inflammatory infiltrate can impair the diagnosis and give rise to false negatives $(1,2)$.

Radiologically, it appears as a unilocular or multilocular well-defined lesion with scalloped margins (10). It can be associated with an included tooth. The differential diagnosis includes the dentigerous or follicular cyst, radicular cyst, periodontal lateral cyst and ameloblastoma, among others $(2,9,12)$. The most frequent location is in mandible (70-75\%), particularly in the angle and mandibular ramus $(1,5,9-11,13)$.

High recurrence rates have been described for this lesion $(4,5,9,12,14)$ mainly depending on the treatment modality as it will determine a complete or incomplete cyst removal $(3,7)$. In addition, a new primary cyst formation in the proximity of the former could be interpreted as a recurrence (8).

Enucleation is the treatment of choice although it can result in a $60 \%$ of recurrences (9). Thus, other adjuvant treatments such as cryotherapy, peripheral ostectomy with rotary instruments, excision of the adhered mucosa, electrocoagulation, Carnoy's solution, marsupialization, decompression and secondary excision or resection have been used $(4,6-8,12)$.

Carnoy's solution (CS) is a cauterizing agent that causes a rapid local fixation. The solution can be used inside the cyst to facilitate a complete remotion of the cystic membrane or directly over the bony bed after the cyst enucleation to detect and eliminate the remaining epithelium of the KOT to diminish the likelihood of a recurrence (5).

The aim of this systematic review was to evaluate the reduction of recurrences associated to the application of Carnoy's solution as adjuvant in the treatment of keratocystic odontogenic tumors.

\section{Material and Methods}

This article follows the Preferred Reporting Items for Systematic Reviews and Meta-Analyses (PRISMA) declaration (15). The selected articles were classified in different levels of evidence by means of the Strength of Recommendation Taxonomy (SORT) criteria (16).

An electronic search in Pubmed (MEDLINE), ScienceDirect and Cochrane databases. The last search was conducted on $27^{\text {th }}$ February 2015. The keywords used were "odontogenic keratocyst", "keratocystic odontogenic tumor", "carnoy's solution", "treatment" and "enucleation". The Boolean operator "AND" was used in order to obtain the most relevant studies.

The inclusion criteria were prospective or retrospective clinical studies using CS as adjuvant treatment for the treatment of primary KOT, articles published in English, including at least 10 patients with a diagnosed KOT. The exclusion criteria were studies with unclear reporting of the treatment applied, nonhuman studies, case reports and lesions associated to Gorlin-Goltz syndrome.

The articles selection was agreed by consensus between two of the authors; first by reading of titles and abstracts of the found bibliographic cites to identify the most relevant studies and then, by means of reading the full-text. No metaanalysis could be done due to the heterogeneity of the studies included.

\section{Results}

The flow chart of the selected articles can be seen in figure 1. Among the 644 studies initially obtained from the search, 605 were excluded by reading the title and abstract. Thus, the complete text of 39 articles was analyzed by the two authors. Sixteen articles (17-32) were excluded; the reasons are detailed in table 1. Thus, twenty-three articles with relevance were selected to be included in the systematic review: 5 systematic reviews $(6,7,9,33,34), 4$ reviews $(1,2,10,11), 10$ retrospective $(3-5,8,14,35-40)$ and 3 prospective studies $(12,13,41)$. Concretely, 13 articles were subjected to data extraction and complete analysis. Despite all these studies had a scientific level 3 and no randomized clinical trials could be found, the authors decided to include them to analyze the available literature. The main results of the included clinical studies are shown in table 2. It should be noted that the studies performed by Zhao et al. (14) and Rao and Kumar (37) did not clearly specify the presence of the parakeratotic component.

The recurrence rates for enucleation varied from 0 to $58.8 \%$ in a period of time ranging from 3 months to 16 years. The use of Carnoy's solution as adjuvant to enucleation had recurrence rates from 0 to $100 \%$ in a time period of 3 months to 9 years. Interestingly, the use of two or more adjuvant techniques had a 0 to $7.9 \%$ of recurrences between 1 and 16 years. Even though, 


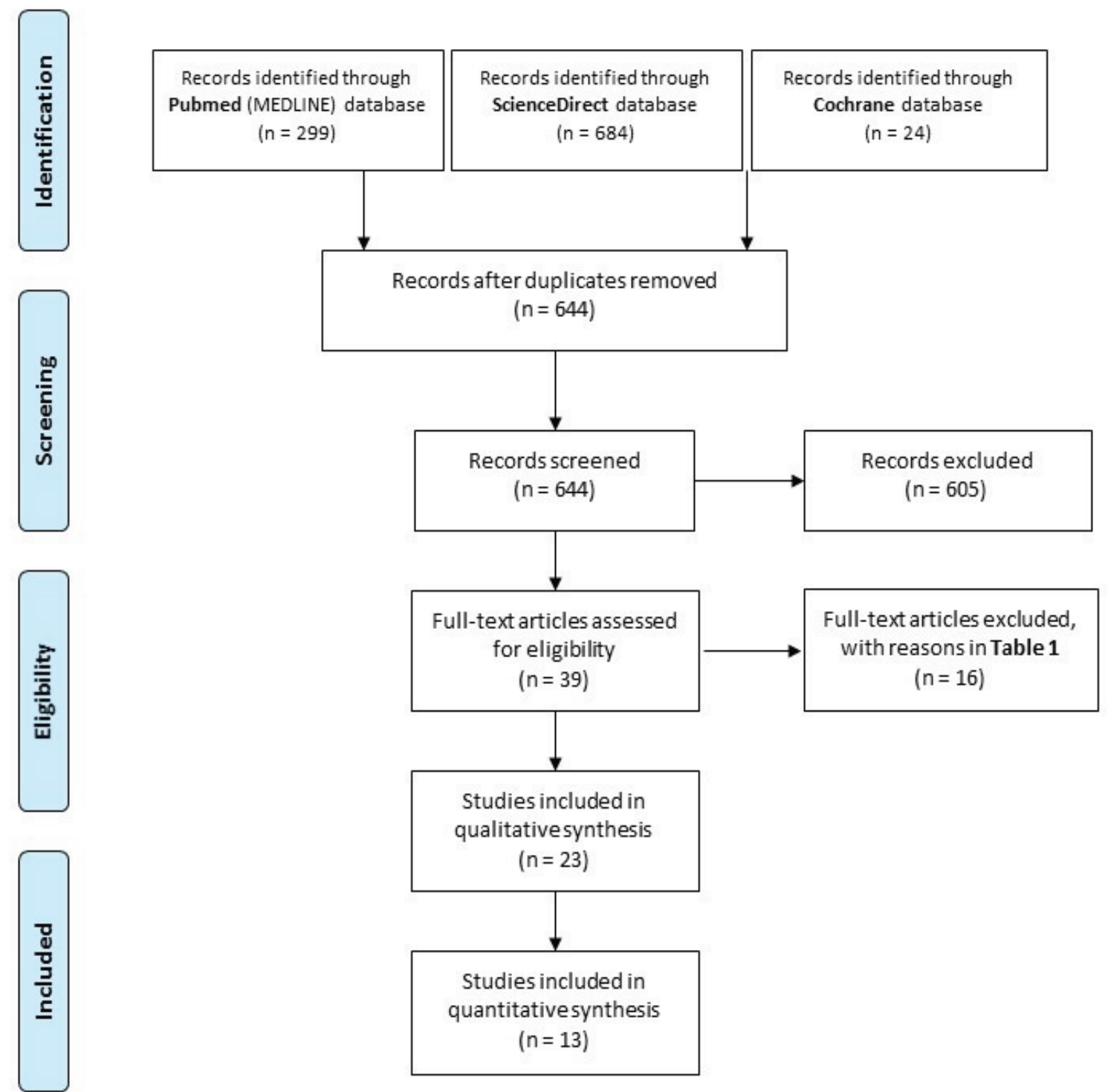

Fig. 1. Flow of articles through the systematic review according to the PRISMA statement.

the treatments that included two or more adjuvant techniques were performed in less patients than the others.

\section{Discussion}

As previously explained, KOT is a benign but aggressive neoplasm of odontogenic origin (3-9). High recurrence rates have been described for this lesion $(4,5,9,12,14,37)$ mainly depending on the treatment modality $(3,7)$. Accordingly, a recently published study (40) quantified Cyclin D1 (CCD1) expression levels, a nuclear protein essential for cell cycle progression, in a series of keratin-producing odontogenic cysts. They concluded that these levels did not predict non syndromic KOT recurrences and that factors not related to the lesion biology could have an influence in the recurrence rates.

Regarding to radiological appearance, lesions with scal- loped and often corticated margins or a multilobular and multilocular appearance can be observed (4, 9,12,14,35). Displacement of impacted or erupted teeth, root resorption, root displacement or extrusion of erupted teeth can occur (4). These lesions are difficult to interpret and easy to be confused with other lesions $(12,14)$. Often asymptomatic, the majority of KOT tends to appear at the mandible, frequently at the mandibular ramus and angle $(3,4,9,14,37)$, although it can also occur in the dentate area of the jaws resembling an odontogenic cyst (12). Even, involvement with an impacted tooth has been described up to $40 \%$ of cases $(4,35)$.

The different treatment modalities can be divided in conservative methods such as enucleation, decompression or marsupialization and in invasive ones, that is, cryosurgery or resection $(6,36)$. Although the most radi- 
Table 1. List of excluded studies and reasons.

\begin{tabular}{|c|c|}
\hline AUTHOR & EXCLUSION CRITERIA \\
\hline Dammer et al. (17) 1997 & Unclear reporting of distribution of the different treatments performed \\
\hline Ghali et al. (18) 2003 & Literature review that does not discuss the use of Carnoy's solution \\
\hline Pitak-Arnnop et al. (19) 2010 & This study does not include the use of Carnoy's solution \\
\hline Boffano et al. (20) 2010 & This study does not include the use of Carnoy's solution \\
\hline Finklestein et al. (21) 2013 & This study does not include the use of Carnoy's solution \\
\hline Sivanmalai et al. (22) 2012 & Case report \\
\hline Kolokythas et al. (23) 2007 & This study does not include the use of Carnoy's solution \\
\hline Zecha et al. (24) 2010 & This study does not include the use of Carnoy's solution \\
\hline Zhao et al. (25) 2012 & All the treated cases are recurrences of a primary KOT \\
\hline Pitak-Arnnop et al. (26) 2010 & Letter to the Editor \\
\hline Rajeshkumar et al. (27) 2013 & Study with only 7 patients diagnosed of KOT \\
\hline Yang et al. (28) 2011 & This study does not include the use of Carnoy's solution \\
\hline Kinard et al. (29) 2013 & Unclear reporting of distribution of the different treatments performed \\
\hline Myoung et al. (30) 2001 & This study does not include the use of Carnoy's solution \\
\hline Tolstunov and Treasure (31) 2008 & Case report \\
\hline Chapelle et al. (32) 2004 & The study involves the treatment of ameloblastomas \\
\hline
\end{tabular}

cal treatments have shown the lower recurrence rates, available evidence does not demonstrate the most effective technique in terms of morbidity and recurrence prevention $(3,5,6,8,38)$.

Enucleation is the most commonly used method to treat the majority of KOT, although with a high rate of recurrences (9). Thus, adjuvant techniques such as the use of CS either before the cyst enucleation or placed directly in the bony bed after the enucleation have been proposed to eliminate residual tissue and so prevent recurrences $(3,5,7,9,14)$. Although CS was initially described to be placed into the cyst lumen before enucleation, most clinicians apply it after $(7,33)$. This aspect could introduce a bias at the time of analyzing the recurrence rates. $\mathrm{CS}$ is a cauterizing and fixating agent that penetrates cancellous spaces in the bone $(3,6,36)$. The time of application is sufficient for 10 to 15 minutes, although if inferior alveolar nerve is visible into the cyst cavity, the application cannot last for more than 3 minutes because of damage of nerve fibers has been described (14).

Some authors defend that techniques such as marsupialization with posterior enucleation are better for larger cysts to reduce the morbidity and to be more conservative $(7,9,14)$. Others state that more invasive techniques such as resection have to be reserved for recurrent KOT with the aim to eliminate satellite cysts or epithelial remnants $(3,7,14)$.

The different adjuvant techniques used in the studies included in this systematic review for the treatment of KOT difficult the analysis of the application of CS as a unique adjuvant treatment apart from the enucleation.
CS has been used in combination with enucleation, peripheral ostectomy, curettage, marsupialization and excision of affected mucosa. As found in this study, not only the use of CS but also the use of multiple adjuvant treatments reduce the recurrence rates compared to enucleation alone.

Regarding to the limitations of the included studies, the differences in the number of participants around the distinct treatments performed difficult to draw conclusions. In a study made by Chow (36), one patient was treated by means of enucleation, CS, peripheral ostectomy and cryotherapy. Although the lesion did not recurred it is not possible to state that the combination of this techniques yields the best results, similarly to other treatments performed in some of the included studies $(5,8,12,35)$. The studies published by Stoelinga (12), Zhao et al.. (14) (both published prior to 2005) and Güler et al. (4) and Rao and Kumar (37) did not specify the histologic variant of the treated odontogenic keratocysts. Thus, a risk of bias in the results could have been introduced. In the retrospective study of Ribeiro et al. (5), they did not specify in which cases the excision of mucosa was done. With regard to the cases that had been followed up, the study from Guler et al. (4) only revisited a $32.5 \%$ of patients and Rao and Kumar (37) did only control visits in 12 from 32 cases.

The retrospective nature of some of the included studies has several limitations such as different lengths of follow-up. The study of Gosau et al. (3) found that lesions treated by means of enucleation plus CS had a recurrence rate of $14.3 \%$ whereas the cases treated with enu- 
Table 2. Characteristics of the clinical studies included in this systematic review regarding to the type of study, the treatments performed, the recurrences and the time of recurrence.

\begin{tabular}{|c|c|c|c|c|c|c|}
\hline Author & Type of study & Treatment & Lesions & Recurrences (\%) & $\begin{array}{c}\text { Recurrence interval } \\
\text { (average) }\end{array}$ & $\begin{array}{l}\text { Follow-up } \\
\text { (average) }\end{array}$ \\
\hline \multirow[t]{2}{*}{ Gosau et al. (3) 2010} & \multirow{2}{*}{ Retrospective } & $\mathrm{E}$ & 22 & $11(50 \%)$ & $\begin{array}{c}7 \mathrm{mo}-68 \mathrm{mo} \\
(35.6 \mathrm{mo})\end{array}$ & $\begin{array}{c}12 \mathrm{mo}-120 \mathrm{mo} \\
(67.4 \mathrm{mo})\end{array}$ \\
\hline & & $\mathrm{E}+\mathrm{CS}$ & 14 & $2(14.3 \%)$ & $1 \mathrm{y}-29 \mathrm{mo}(18.5 \mathrm{mo})$ & $\begin{array}{c}12 \mathrm{mo}-120 \mathrm{mo} \\
(45.6 \mathrm{mo})\end{array}$ \\
\hline \multirow{3}{*}{ Güler et al. (4) 2012} & \multirow{3}{*}{ Retrospective } & $\mathrm{E}$ & 18 & 0 & - & \multirow{3}{*}{$20 y-29 y$} \\
\hline & & $\mathrm{E}+\mathrm{CS}$ & 10 & 0 & - & \\
\hline & & $\mathrm{E}+\mathrm{M}+\mathrm{CS}$ & 15 & 0 & - & \\
\hline \multirow{2}{*}{$\begin{array}{l}\text { Ribeiro-Junior et al. } \\
\text { (5) } 2012\end{array}$} & \multirow{2}{*}{ Retrospective } & $\mathrm{E}+\mathrm{PO}+\mathrm{CS}$ & 9 & 0 & - & \multirow{2}{*}{$\begin{array}{c}18 \mathrm{mo}-78 \mathrm{mo} \\
(42.9 \mathrm{mo})\end{array}$} \\
\hline & & $\mathrm{M}+\mathrm{E}+\mathrm{CS}+\mathrm{PO}$ & 2 & 0 & - & \\
\hline \multirow{5}{*}{$\begin{array}{l}\text { Morgan et al. } \\
\quad \text { (8) } 2005\end{array}$} & \multirow{5}{*}{ Retrospective } & E & 11 & $6(54.5 \%)$ & $\begin{array}{c}3 \mathrm{mo}-106 \mathrm{mo} \\
(49.1 \mathrm{mo})\end{array}$ & \multirow{5}{*}{$\begin{array}{c}13 \mathrm{mo}-288 \mathrm{mo} \\
(63.7 \mathrm{mo})\end{array}$} \\
\hline & & $\mathrm{E}+\mathrm{CS}$ & 2 & $1(50 \%)$ & $\begin{array}{c}3 \mathrm{mo}-106 \mathrm{mo} \\
(49.1 \mathrm{mo})\end{array}$ & \\
\hline & & $\mathrm{E}+\mathrm{PO}$ & 11 & $2(18.2 \%)$ & $\begin{array}{c}3 \mathrm{mo}-106 \mathrm{mo} \\
(49.1 \mathrm{mo})\end{array}$ & \\
\hline & & $\mathrm{E}+\mathrm{PO}+\mathrm{CS}$ & 13 & 0 & - & \\
\hline & & $\mathrm{R}$ & 3 & 0 & - & \\
\hline \multirow{4}{*}{ Stoelinga (12) 2001} & \multirow{4}{*}{ Prospective } & $\mathrm{E}$ & 33 & $6(18.2 \%)$ & $1 \mathrm{y}-16 \mathrm{y}$ & \multirow{4}{*}{$2 y-25 y(11.8 y)$} \\
\hline & & $\mathrm{E}+\mathrm{EAM}$ & 6 & 0 & - & \\
\hline & & $\mathrm{E}+\mathrm{CS}$ & 5 & 0 & - & \\
\hline & & $\mathrm{E}+\mathrm{EAM}+\mathrm{CS}$ & 38 & $3(7.9 \%)$ & $1 y-16 y$ & \\
\hline \multirow{4}{*}{$\begin{array}{l}\text { Titinchi \& Nortje } \\
\text { (13) } 2012\end{array}$} & \multirow{4}{*}{ Prospective } & $\mathrm{E}$ & 50 & $15(30 \%)$ & $13 \mathrm{mo}$ & \multirow{4}{*}{ (19.8 mo) } \\
\hline & & $\mathrm{M}$ & 5 & $3(60 \%)$ & $23.5 \mathrm{mo}$ & \\
\hline & & $\mathrm{E}+\mathrm{CS}$ & 9 & $1(11.1 \%)$ & $12.6 \mathrm{mo}$ & \\
\hline & & $\mathrm{R}$ & 1 & 0 & - & \\
\hline \multirow{4}{*}{ Zhao et al. (14) 2002} & \multirow{4}{*}{ Retrospective } & $\mathrm{E}$ & 163 & $29(17.8 \%)$ & $2 y-13 y$ & \multirow{4}{*}{$3 y-29 y(7.8 y)$} \\
\hline & & $\mathrm{E}+\mathrm{CS}$ & 29 & $2(6.7 \%)$ & $2 y-13 y$ & \\
\hline & & $E+M$ & 11 & 0 & - & \\
\hline & & $\mathrm{R}$ & 52 & 0 & - & \\
\hline \multirow{5}{*}{$\begin{array}{l}\text { Chirapathomsakul } \\
\text { et al. (35) } 2006\end{array}$} & \multirow{5}{*}{ Retrospective } & $\mathrm{M}$ & 6 & $1(16.7 \%)$ & $2 y-10 y$ & \multirow{5}{*}{$1 \mathrm{y}-14.6 \mathrm{y}$} \\
\hline & & $\mathrm{E}$ & 15 & $2(13.3 \%)$ & $12 \mathrm{mo}-56 \mathrm{mo}$ & \\
\hline & & $\mathrm{E}+\mathrm{CS}$ & 5 & $1(20 \%)$ & $2 y-10 y$ & \\
\hline & & $\mathrm{E}+\mathrm{CU}$ & 2 & $2(100 \%)$ & $2 y-10 y$ & \\
\hline & & $\mathrm{R}$ & 7 & $1(14.2 \%)$ & $18 \mathrm{mo}-68 \mathrm{mo}$ & \\
\hline \multirow{3}{*}{ Chow (36) 1998} & \multirow{3}{*}{ Retrospective } & $\mathrm{E}+\mathrm{PO}$ & 52 & $5(9.6 \%)$ & $2 y-10 y$ & \\
\hline & & $\mathrm{E}+\mathrm{PO}+\mathrm{CS}$ & 23 & $1(4.3 \%)$ & $2 y$ & Not cited \\
\hline & & $\mathrm{E}+\mathrm{PO}+\mathrm{CS}+\mathrm{CR}$ & 1 & 0 & - & \\
\hline $\begin{array}{c}\text { Rao \& Kumar } \\
\text { (37) } 2012 \\
\end{array}$ & Retrospective & $\mathrm{E}+\mathrm{CS}$ & 32 & $2(6.3 \%)$ & $2.8 \mathrm{y}$ & $7 y-17 y(2.8 y)$ \\
\hline & & $\mathrm{E}+\mathrm{PO}$ & 49 & $11(22.4 \%)$ & $8 \mathrm{mo}-9 \mathrm{y}(5 \mathrm{y})$ & \\
\hline Sánchez-Burgos et al. & Retrosnective & $\mathrm{E}+\mathrm{CS}$ & 2 & $2(100 \%)$ & $8 \mathrm{mo}-9 \mathrm{y}(5 \mathrm{y})$ & $8 \mathrm{mo}-9 \mathrm{y}(5 \mathrm{y})$ \\
\hline (38) 2014 & Retrospective & M & 2 & $1(50 \%)$ & $8 \mathrm{mo}-9 \mathrm{y}(5 \mathrm{y})$ & $0110-3 y(3 y)$ \\
\hline & & $\mathrm{R}$ & 2 & 0 & - & \\
\hline & & E & 17 & $10(58.8 \%)$ & $9 \mathrm{mo}-41 \mathrm{mo}$ & \\
\hline (39) 2011 & Retrospective & $\mathrm{E}+\mathrm{CS}$ & 1 & 0 & - & $1 y-7 y \quad(3 y)$ \\
\hline & & $\mathrm{E}+\mathrm{CR}$ & 4 & $2(50 \%)$ & $17 \mathrm{mo}-30 \mathrm{mo}$ & \\
\hline $\begin{array}{l}\text { Apajalahti et al. } \\
\text { (41) } 2011\end{array}$ & Prospective & $\mathrm{E}+\mathrm{CS}$ & 46 & $19(39 \%)$ & $0.6 \mathrm{y}-3.4 \mathrm{y}(2.2 \mathrm{y})$ & $1 \mathrm{y}->8 \mathrm{y}(4.7 \mathrm{y})$ \\
\hline
\end{tabular}

The treatments that include the use of Carnoy's solution appear highlighted in grey. E: enucleation, EAM: excision of adhered mucosa, CS: Carnoy's solution, CU: curettage, CR: cryotherapy, M: marsupialization, PO: peripheral ostectomy, R: resection, mo: months, ys: years. 
cleation had a $50 \%$ of recurrences. However, the length of follow-up was shorter in the first group (18.5 months as average) than in the enucleation group (36.5 months). Most studies recommend the need of a long-term follow-up at regular intervals after surgery $(7,8,35,38,39)$. A follow-up of 5 years or more is recommended because some recurrences have been reported 16 years after the initial treatment (12). Morgan et al. (8) studied the possibility of having more recurrences because of a longer follow-up and they did not found significant differences between the mean time to recurrence for patients with recurrence and the mean follow-up for patients without recurrence. As stated by Antonoglou et al. (34), the different times of follow-up among the studies and the lack of histopathologic data in some of them could introduce a bias in the results. Moreover, there are no randomized clinical trials performed for the treatment of KOT, as stated by the Sharif and Oliver systematic review (9). Future research with randomized and/or controlled clinical studies, with similar samples or number of lesions treated and with a long-term follow-up is needed to obtain consistent results.

\section{Conclusions}

The lack of randomized clinical trials, the methodological differences and the low level of evidence of the included studies allow to conclude that the use of Carnoy's solution as adjuvant therapy for the treatment of KOT has a grade $\mathrm{C}$ recommendation and that there is not a clear reduction in the recurrences.

\section{References}

1. Philipsen H. The keratocystic odontogenic tumour. In: Barnes L, Eveson JW, Reichart P, Sidransky D, editors. World Health Organization Classification of Tumours Pathology \& Genetics Head and Neck Tumours. Lyon: IARC; 2005. p. 306-7.

2. Stoelinga PJ. Excision of the overlying, attached mucosa, in conjunction with cyst enucleation and treatment of the bony defect with carnoy solution. Oral Maxillofac Surg Clin North Am. 2003; $15: 407-14$

3. Gosau M, Draenert FG, Müller S, Frerich B, Bürgers R, Reichert TE, et al. Two modifications in the treatment of keratocystic odontogenic tumors (KCOT) and the use of Carnoy's solution (CS)-A retrospective study lasting between 2 and 10 years. Clin Oral Investig. 2010;14:27-34.

4. Güler N, Sençift K, Demirkol O. Conservative management of keratocystic odontogenic tumors of jaws. ScientificWorldJournal. 2012;2012:680397.

5. Ribeiro-Junior O, Borba A, Alves C, de Gouveia M, Coracin F, Guimarães Júnior J. Keratocystic odontogenic tumors and Carnoy's solution: Results and complications assessment. Oral Dis. 2012;18:548-57

6. Kaczmarzyk T, Mojsa I, Stypulkowska J. A systematic review of the recurrence rate for keratocystic odontogenic tumour in relation to treatment modalities. Int J Oral Maxillofac Surg. 2012;41:756-67.

7. Johnson NR, Batstone MD, Savage NW. Management and recurrence of keratocystic odontogenic tumor: A systematic review. Oral Surg Oral Med Oral Pathol Oral Radiol. 2013;116:271-6.
8. Morgan TA, Burton CC, Qian F. A retrospective review of treatment of the odontogenic keratocyst. J Oral Maxillofac Surg. 2005;63:635-9

9. Sharif F, Oliver R. Interventions for the treatment of keratocystic odontogenic tumours (KCOT, odontogenic keratocysts (OKC). Cochrane Database Syst Rev. 2010;9:CD008464.

10. Mendes RA, Carvalho JFC, Van der Waal I. Characterization and management of the keratocystic odontogenic tumor in relation to its histopathological and biological features. Oral Oncol. 2010;46:21925

11. Williams TP, Connor FA Jr. Surgical management of the odontogenic keratocyst: aggressive approach. J Oral Maxillofac Surg. 1994;52:964-6.

12. Stoelinga PJ. Long-term follow-up on keratocysts treated according to a defined protocol. Int J Oral Maxillofac Surg. 2001;30:14-25.

13. Titinchi F, Nortje CJ. Keratocystic odontogenic tumor: A recurrence analysis of clinical and radiographic parameters. Oral Surg Oral Med Oral Pathol Oral Radiol. 2012;114:136-42.

14. Zhao YF, Wei JX, Wang SP. Treatment of odontogenic keratocysts: a follow-up of 255 Chinese patients. Oral Surg Oral Med Oral Pathol Oral Radiol Endod. 2002;94:151-6.

15. Moher D, Liberati A, Tetzlaff J, Altman DG, The PRISMA Group. Preferred Reporting Items for Systematic Reviews and MetaAnalyses: The PRISMA Statement. PLoS Med. 2009;6:1000097.

16. Ebell MH, Siwek J, Weiss BD, Woolf SH, Susman J, Ewigman

$B$, et al. Strength of recommendation taxonomy (SORT): A patientcentered approach to grading evidence in the medical literature. J Am Board Fam Pract. 2004;17:59-67.

17. Dammer R, Niederdellmann H, Dammer P, Nuebler-Moritz M. Conservative or radical treatment of keratocysts: a retrospective review. Br J Oral Maxillofac Surg. 1997;35:46-8.

18. Ghali GE, Connor MS. Surgical management of the odontogenic keratocyst. Oral Maxillofac Surg Clin North Am. 2003;15:383-92.

19. Pitak-Arnnop P, Chaine A, Oprean N, Dhanuthai K, Bertrand JC, Bertolus C. Management of odontogenic keratocysts of the jaws: a ten-year experience with 120 consecutive lesions. J Craniomaxillofac Surg. 2010;38:358-64.

20. Boffano P, Ruga E, Gallesio C. Keratocystic odontogenic tumor (odontogenic keratocyst): preliminary retrospective review of epidemiologic, clinical, and radiologic features of 261 lesions from University of Turin. J Oral Maxillofac Surg. 2010;68:2994-9.

21. Finkelstein MW, Hellstein JW, Lake KS, Vincent SD. Keratocystic odontogenic tumor: a retrospective analysis of genetic, immunohistochemical and therapeutic features. Proposal of a multicenter clinical survey tool. Oral Surg Oral Med Oral Pathol Oral Radiol. 2013;116:75-83.

22. Sivanmalai S, Kandhasamy K, Prabu N, Prince CN, Prabu CS. Carnoy's solution in the mangement of odontogenic keratocyst. J Pharm Bioallied Sci. 2012;4:183-5.

23. Kolokythas A, Fernandes RP, Pazoki A, Ord RA. Odontogenic keratocyst: to decompress or not to decompress? A comparative study of decompression and enucleation versus resection/peripheral ostectomy. J Oral Maxillofac Surg. 2007;65:640-4.

24. Zecha JA, Mendes RA, Lindeboom VB, van der Waal I. Recurrence rate of keratocystic odontogenic tumor after conservative surgical treatment without adjunctive therapies - A 35-year single institution experience. Oral Oncol. 2010;46:740-2.

25. Zhao Y, Liu B, Cheng G, Wang SP, Wang YN. Recurrent keratocystic odontogenic tumours: report of 19 cases. Dentomaxillofac Radiol. 2012;41:96-102.

26. Pitak-Arnnop P. Enucleation of keratocystic odontogenic tumours: study interpretation, technical refinement and future research. Clin Oral Investig. 2010;14:719-21.

27. Rajeshkumar BP, Rai KK, Geetha NT, Shivakumar HR, Upasi AP. Carnoy's in aggressive lesions: Our experience. J Maxillofac Oral Surg. 2013;12:42-7. 
28. Yang S, Park YI, Choi SY, Kim JW, Kim CS. A retrospective study of 220 cases of keratocystic odontogenic tumor (KCOT) in 181 patients. Asian J Oral Maxillofac Surg. 2011;23:117-21.

29. Kinard BE, Chuang SK, August M, Dodson TB. How well do we manage the odontogenic keratocyst? J Oral Maxillofac Surg. 2013;71:1353-8.

30. Myoung H, Hong SP, Hong SD, Lee JI, Lim CY, Choung PH, et al. Odontogenic keratocyst: Review of 256 cases for recurrence and clinicopathologic parameters. Oral Surg Oral Med Oral Pathol Oral Radiol Endod. 2001;91:328-33.

31. Tolstunov L, Treasure T. Surgical treatment algorithm for odontogenic keratocyst: combined treatment of odontogenic keratocyst and mandibular defect with marsupialization, enucleation, iliac crest bone graft, and dental implants. J Oral Maxillofac Surg. 2008;66:1025-36.

32. Chapelle KA, Stoelinga PJ, de Wilde PC, Brouns JJ, Voorsmit RA. Rational approach to diagnosis and treatment of ameloblastomas and odontogenic keratocysts. Br J Oral Maxillofac Surg. 2004;42:38190.

33. Blanas N, Freund B, Schwartz M, Furst IM. Systematic review of the treatment and prognosis of the odontogenic keratocyst. Oral Surg Oral Med Oral Pathol Oral Radiol Endod. 2000;90:553-8.

34. Antonoglou GN, Sándor GK, Koidou VP, Papageorgiou SN. Non-syndromic and syndromic keratocystic odontogenic tumors: Systematic review and meta-analysis of recurrences. J Craniomaxillofac Surg. 2014;42:364-71.

35. Chirapathomsakul D, Sastravaha P, Jansisyanont P. A review of odontogenic keratocysts and the behavior of recurrences. Oral Surg Oral Med Oral Pathol Oral Radiol Endod. 2006;101:5-9.

36. Chow HT. Odontogenic keratocyst: a clinical experience in Singapore. Oral Surg Oral Med Oral Pathol Oral Radiol Endod. 1998;86:573-7.

37. Rao K, Kumar S. The use of enucleation and chemical cauterization (Carnoy's) in the management of odontogenic keratocyst of the jaws. Indian J Otolaryngol Head Neck Surg. 2014;66:8-12.

38. Sánchez-Burgos R, González-Martín-Moro J, Pérez-Fernández E, Burgueño-García M. Clinical, radiological and therapeutic features of keratocystic odontogenic tumours: A study over a decade. J Clin Exp Dent. 2014;6:259-64.

39. Schussel JL, Stramandinoli RT, Dissenha JL, Avila LF, Sassi LM. Retrospective study of 25 cases of keratocystic odontogenic tumor: Epidemiology and treatment. J Contemp Dent Pract. 2011;12:100-3. 40. Vera-Sirera B, Forner-Navarro L, Vera-Sempere F. Differential expression of cyclin d1 in keratin-producing odontogenic cysts. Med Oral Patol Oral Cir Bucal. 2015;20:59-65.

41. Apajalahti S, Hagström J, Lindqvist C, Suomalainen A. Computerized tomography findings and recurrence of keratocystic odontogenic tumor of the mandible and maxillofacial region in a series of 46 patients. Oral Surg Oral Med Oral Pathol Oral Radiol Endod. 2011;111:29-37.

\section{Acknowledgements}

The authors declare no conflict of interest and no source of funding. This study has been performed by the research group "Odontological and Maxillofacial Pathology and Therapeutics" of the IDIBELL Institute.

Conflict of Interest

The authors have declared that no conflict of interest exist. 